\title{
Access to primary care and other health care use among western Canadians with chronic conditions: a population-based survey
}

\author{
Robert G. Weaver MSc, Braden J. Manns MD MSc, Marcello Tonelli MD SM, Claudia Sanmartin PhD, \\ David J.T. Campbell MD MSc, Paul E. Ronksley PhD, Richard Lewanczuk MD PhD, Ted C. Braun MD, \\ Deirdre Hennessy PhD, Brenda R. Hemmelgarn MD PhD
}

\section{Abstract}

Background: For adults with chronic conditions, access to primary care, including multidisciplinary care, is associated with better outcomes. Few studies have assessed barriers to such care. We sought to describe barriers to primary care, including care from allied health professionals, for adults with chronic conditions.

Methods: We surveyed western Canadians aged 40 years or older who had hypertension, diabetes, heart disease or stroke about access to primary care and other use of health care. Using log binomial regression, we determined the association between sociodemographic variables and several indicators of access to primary care and care from allied health professionals.

Results: Of the 2316 people who were approached, 1849 (79.8\%) completed the survey. Most of the respondents (95.1\%) had a regular medical doctor, but two-thirds $(68.1 \%)$ did not have after-hours access. Only $6.1 \%$ indicated that allied health professionals were involved in their care, although most respondents (87.3\%) indicated they would be willing to see a nurse practitioner if their primary care physician was not available. Respondents who were obese or less than 65 years of age were less likely to have a regular medical doctor. Individuals who had diabetes, lived in a rural area, were residents of Alberta or had poorer health were more likely to have allied health professionals involved in their care.

Interpretation: The survey results identified barriers to accessing primary care for people with chronic conditions. Opportunities for improving access to primary care may include greater involvement by allied health professionals, such as nurse practitioners.

$\mathrm{P}$ eople with chronic conditions such as diabetes and hypertension often follow complex treatment regimens that include medications, regular monitoring or adherence to lifestyle changes. ${ }^{1}$ Access to primary care is a critical first step in receiving appropriate care for management of chronic conditions and has been shown to be inversely related to the rate of preventable hospital admissions in this population. ${ }^{2}$ In addition to access to and availability of a primary care physician, multidisciplinary care involving allied health professionals, such as nurses and dietitians, may lead to improved outcomes for people with chronic conditions. ${ }^{3-5}$

Not all patients with chronic conditions have reasonable access to primary care and associated allied health professionals, and few studies have directly assessed the frequency and types of barriers to accessing primary care. To better understand potentially modifiable barriers to care for those with chronic conditions related to cardiovascular disease, as well as barriers to the self-management of these conditions, Statistics Canada, in collaboration with the Interdisciplinary Chronic
Disease Collaboration (www.icdc.ca), conducted the Barriers to Care for People with Chronic Health Conditions survey. This was a population-based survey of people aged 40 years or older in western Canada with diabetes, hypertension, heart disease or stroke. Hypertension and diabetes were included given their association with vascular disease.

Our objectives were to describe access to primary care (i.e., primary care physicians and other health professionals) and other use of health care (i.e., specialist care, hospital admissions and emergency department visits) among adults with these chronic conditions, and to identify potentially

Competing interests: None declared.

This article has been peer reviewed.

Correspondence to: Brenda Hemmelgarn, brenda.hemmelgarn@albertahealthservices.ca

CMAJ Open 2014.DOI:10.9778/cmajo.20130045 


\section{OPEN}

Research

modifiable barriers at the patient, provider and system level related to lack of access to primary care.

\section{Methods}

\section{Data sources}

We analyzed data from the 2012 Barriers to Care for People with Chronic Health Conditions survey. Adults aged 40 years or older residing in the 4 western Canadian provinces (British Columbia, Alberta, Saskatchewan and Manitoba) who responded to the 2011 Canadian Community Health Survey (CCHS) and who indicated they had received a diagnosis from a health professional of diabetes, heart disease, hypertension or a prior stroke, were eligible for inclusion in the survey. Members of the Canadian Forces, First Nations people living on reserves and people in long-term care were not eligible for inclusion in the CCHS. The response rate to the CCHS in the 4 provinces was $68.7 \%$; nonresponse was addressed through Statistics Canada's complex weighting techniques. ${ }^{6}$

The Interdisciplinary Chronic Disease Collaboration developed the current survey in collaboration with subject matter experts at Statistics Canada. The survey was tested in Calgary, Alberta, in July 2011, through one-on-one interviews and focus groups with participants who were representative of the patient population, and was revised accordingly. ${ }^{7}$ A number of items in the sections of the survey relevant to this study are included in Appendix 1 (available at www.cmajopen.ca /content/2/1/E27/suppl/DC1). Computer-assisted telephone interviews were conducted by Statistics Canada in February and March 2012. Of the 2316 people selected for inclusion, 1849 (79.8\%) completed the survey. With participants' permission, responses were linked to their $2011 \mathrm{CCHS}$ responses, which provided detailed demographic, lifestyle and related information.

\begin{tabular}{|c|c|c|c|}
\hline \multirow[b]{2}{*}{ Characteristic } & \multicolumn{3}{|c|}{ Group, \% $(95 \% \mathrm{Cl})^{*}$} \\
\hline & Total & 1 chronic condition & $\geq 2$ chronic conditions \\
\hline Total & - & $67.8(64.8-70.8)$ & $32.2(29.2-35.2)$ \\
\hline Sex, male & $49.9(46.0-53.8)$ & $47.9(43.1-52.7)$ & $54.2(48.0-60.4)$ \\
\hline \multicolumn{4}{|l|}{ Age category, yr } \\
\hline $40-64$ & $48.8(45.7-52.1)$ & $54.4(50.3-58.5)$ & $37.2(31.1-43.4)$ \\
\hline $65-74$ & $26.9(23.9-29.8)$ & $25.4(21.7-29.0)$ & $30.0(24.7-35.4)$ \\
\hline$\geq 75$ & $24.3(21.5-27.0)$ & $20.2(16.9-23.6)$ & $32.7(27.0-38.4)$ \\
\hline Rural residence & $17.5(14.6-20.5)$ & $17.1(13.4-20.9)$ & $18.3(14.1-22.5)$ \\
\hline \multicolumn{4}{|l|}{ Household income } \\
\hline$<\$ 30000$ & $21.8(18.9-24.7)$ & $18.5(15.2-21.8)$ & $28.6(23.1-34.1)$ \\
\hline$\$ 30000-\$ 54999$ & $27.4(24.3-30.4)$ & $23.8(20.2-27.3)$ & $34.9(29.5-40.4)$ \\
\hline$\$ 55000-\$ 94999$ & $24.9(21.5-28.4)$ & $27.0(22.4-31.6)$ & $20.6(15.7-25.4)$ \\
\hline$\geq \$ 95000$ & $26.0(22.3-29.6)$ & $30.7(25.8-35.6)$ & $15.9(11.4-20.4)$ \\
\hline Median household income, $\$$ & 55000 & 63000 & 43000 \\
\hline \multicolumn{4}{|l|}{ Marital status } \\
\hline Married/common-law & $66.9(63.2-70.6)$ & $69.2(64.7-73.7)$ & $62.2(56.6-67.8)$ \\
\hline Widowed/separated/divorced/single & $33.1(29.4-36.8)$ & $30.8(26.3-35.3)$ & $37.8(32.2-43.4)$ \\
\hline \multicolumn{4}{|l|}{ Level of education } \\
\hline Did not graduate from high school & $21.3(18.6-24.1)$ & $18.7(15.5-21.9)$ & $26.8(21.6-32.0)$ \\
\hline $\begin{array}{l}\text { Graduated from high school and/or completed } \\
\text { some postsecondary education }\end{array}$ & $22.0(18.9-25.1)$ & $22.3(18.3-26.2)$ & $21.5(16.2-26.8)$ \\
\hline $\begin{array}{l}\text { Graduated from a postsecondary program (did not } \\
\text { complete a Bachelor's degree) }\end{array}$ & $37.7(33.9-41.5)$ & $37.1(32.2-42.0)$ & $38.8(33.0-44.6)$ \\
\hline Completed a Bachelor's or higher degree & $19.0(15.6-22.4)$ & $21.9(17.3-26.5)$ & $12.9(9.1-16.7)$ \\
\hline \multicolumn{4}{|l|}{ BMI category† } \\
\hline Normal/underweight & $23.3(19.8-26.7)$ & $24.7(20.3-29.2)$ & $20.0(14.7-25.4)$ \\
\hline Overweight & $36.7(32.5-40.8)$ & $38.0(32.9-43.2)$ & $33.7(27.6-29.9)$ \\
\hline Obese & $40.1(36.2-44.0)$ & $37.2(32.2-42.3)$ & $46.2(40.1-52.3)$ \\
\hline \multirow[t]{2}{*}{ Mean BMI } & $29.4(29.1-29.6)$ & $28.9(28.6-29.2)$ & $30.3(29.8-30.8)$ \\
\hline & & & Continued \\
\hline
\end{tabular}




\section{Key variables}

\section{Access to primary care}

Respondents were asked whether they had a regular medical doctor; if not, where they received their health care; and how often they were seen by the same medical doctor or nurse. They were also asked whether their regular medical doctor provided after-hours access (where patients could be seen outside of typical office hours). In addition, respondents were asked if there were other health professionals (such as nurse practitioners or nutritionists) working in the same office as their primary care physicians, and if so, whether they were involved in their care. They were also asked how many contacts they had had with a nurse in the past 12 months about their chronic condition, excluding hospital admissions. Finally, respondents were asked if they would be willing to see a nurse practitioner if their regular doctor was not available. Not having a regular medical doctor, having another health professional involved in care and having contact with a nurse in the prior year were the outcomes and indicators of access to primary care.

\section{Other health care use}

Respondents were asked how often in the past 12 months they had seen a specialist for their chronic condition and how many different physicians were involved in their care. Those who had not seen a specialist were asked why not. Respondents were also asked if they had been admitted to hospital or had visited an emergency department for their chronic condition in the prior 12 months. Those who had visited an emergency department for their chronic condition were asked whether they thought this could have been avoided had their regular provider been available; this item was also used as an outcome indicating poor access to primary care.

\section{Other variables}

We categorized respondents by their chronic condition(s) and by whether they had received a diagnosis of 1 or more than 1 of the 4 selected chronic conditions. We obtained sociodemographic variables from the CCHS, including age, sex, education level, household income, ethnic origin (white, Aboriginal or other), rural versus urban residence and Canadian-born versus immigrant. We calculated body mass index category from self-reported weight and height, using an adjustment for self-reported data. ${ }^{8}$

\section{Analysis}

Frequency weights for the survey were calculated by Statistics Canada based on the weights from the 2011 CCHS, which

\begin{tabular}{|c|c|c|c|}
\hline \multirow[b]{2}{*}{ Characteristic } & \multicolumn{3}{|c|}{ Group, \% $(95 \% \mathrm{Cl})^{*}$} \\
\hline & Total & 1 chronic condition & $\geq 2$ chronic conditions \\
\hline \multicolumn{4}{|l|}{ Province of residence } \\
\hline British Columbia & $44.5(41.3-47.7)$ & $43.8(39.2-48.4)$ & $46.0(40.7-51.3)$ \\
\hline Alberta & $31.7(28.8-34.6)$ & $33.9(29.8-37.9)$ & $27.0(22.5-31.6)$ \\
\hline Saskatchewan & $10.8 \quad(9.4-12.1)$ & $9.7 \quad(8.0-11.5)$ & $13.0 \quad(9.7-16.2)$ \\
\hline Manitoba & $13.0(11.1-15.0)$ & $12.6 \quad(9.9-15.4)$ & $14.0(10.1-17.9)$ \\
\hline \multicolumn{4}{|l|}{ Ethnic origin } \\
\hline White & 86.7 (83.5-89.9) & $87.3(83.2-91.4)$ & $85.4(80.6-90.1)$ \\
\hline Aboriginal & $4.2(2.9-5.5)$ & $3.3(1.8-4.9)$ & $6.0 \quad(3.3-8.7)$ \\
\hline Other & $9.1 \quad(6.0-12.2)$ & $9.4 \quad(5.3-13.4)$ & $8.7 \quad(4.6-12.7)$ \\
\hline \multicolumn{4}{|l|}{ Self-perceived health } \\
\hline Excellent/very good & $36.8(33.0-40.6)$ & $43.8(38.7-48.9)$ & $22.1(17.1-27.1)$ \\
\hline Good & $40.2(36.1-44.2)$ & $41.1(35.7-46.4)$ & $38.3(32.1-44.5)$ \\
\hline Fair/poor & $23.0(20.1-25.9)$ & $15.1(12.0-18.3)$ & $39.6(33.5-45.6)$ \\
\hline \multicolumn{4}{|c|}{ Type of chronic condition $\ddagger$} \\
\hline Hypertension & $82.1(79.3-84.8)$ & $63.5(60.0-67.0)$ & $36.5(33.0-40.0)$ \\
\hline Diabetes & $26.3(23.7-28.9)$ & $33.4(27.0-39.7)$ & $66.6(60.3-73.0)$ \\
\hline Heart disease & $21.5(18.7-24.3)$ & $29.6(23.0-36.2)$ & $70.4(63.8-77.0)$ \\
\hline Stroke & $8.0 \quad(6.4-9.6)$ & $9.0 \quad(3.0-15.1)$ & $91.0(84.9-97.0)$ \\
\hline \multicolumn{4}{|c|}{$\begin{array}{l}\text { Note: } \mathrm{BMI}=\text { body mass index, } \mathrm{Cl}=\text { confidence interval. } \\
\text { *Unless stated otherwise. All proportions }(\%) \text { and } 95 \% \text { Cls were weighted and bootstrapped as per Statistics Canada guidelines. } N \text { values for } \\
\text { subgroups are therefore not meaningful and have been excluded. } \\
\text { tBMI was corrected for self-report bias. } \\
\text { tThe percentages in the final } 2 \text { columns reflect the proportion of respondents with that chronic condition who had } 1 \text { or more than } 1 \text { of the chronic } \\
\text { conditions. }\end{array}$} \\
\hline
\end{tabular}




\section{OPEN}

Research

were adjusted for nonresponse by province, disease and age group. After weighting, the sample was representative of the population aged 40 years and older residing in the western provinces with the selected chronic conditions. ${ }^{9}$ Variance estimates were calculated using 500 bootstrap survey weights. We conducted all analyses with these frequency and bootstrap weights using Stata 11.2.

We stratified variables related to access to primary care and other health care use by the number and type of chronic conditions. We also fit multivariable log binomial regression models to determine the prevalence rate ratios for characteristics associated with the outcomes identified above: not having a regular medical doctor; receiving care from other professionals in the primary care physician's office; having seen or talked to a nurse about the chronic condition; and reporting an emergency department visit for the chronic condition that was perceived as avoidable. We constructed models using a forward stepwise approach and tested variables (see respondent characteristics in Table 1 for a list of the variables) for inclusion (using $p<0.05$ ) that we had identified a priori as being potentially associated with the outcomes. If the log binomial models did not converge, we used logistic models.
The Conjoint Health Research Ethics Board of the University of Calgary and the Health Research Ethics Board of the University of Alberta gave ethics approval for the study.

\section{Results}

\section{Demographic and baseline characteristics}

Of the 1849 people who completed the survey, about half $(51.2 \%)$ were 65 years of age or older, with an equal proportion of men and women (Table 1). Most respondents (76.8\%) were overweight or obese, and $36.8 \%$ reported their health as excellent or very good, despite having at least 1 chronic condition. Median household income was \$55 000 among respondents: $\$ 80000$ among those under 65 years of age and $\$ 40000$ among those aged 65 and over. Most respondents $(82.1 \%)$ had hypertension, and $26.3 \%$ had diabetes. A total of $32.2 \%$ had more than 1 of the chronic conditions (Table 1).

\section{Access to and use of primary care resources}

Most respondents $(95.1 \%)$ reported that they had a regular medical doctor and most $(78.0 \%)$ indicated they always

Table 2: Access to and use of primary care resources, by number of chronic conditions

\begin{tabular}{|c|c|c|c|}
\hline \multirow[b]{2}{*}{ Primary care resource } & \multicolumn{3}{|c|}{ Group, \% $(95 \% \mathrm{Cl})^{\star}$} \\
\hline & Total & 1 chronic condition & $\geq 2$ chronic conditions \\
\hline \multicolumn{4}{|l|}{ Have a regular medical doctor } \\
\hline Yes & $95.1(93.2-97.1)$ & $94.2(91.4-96.9)$ & $97.2(95.2-99.2)$ \\
\hline No & $4.9(2.9-6.8)$ & $5.8(3.1-8.6)$ & $2.8(0.8-4.8)$ \\
\hline \multicolumn{4}{|c|}{ Frequency of care by the same physician or nurse } \\
\hline Always & $78.0(74.5-81.5)$ & $76.4(71.8-81.1)$ & $81.3(76.4-86.2)$ \\
\hline Often, sometimes, rarely or never & $22.0(18.5-25.5)$ & $23.6(18.9-28.2)$ & $18.7(13.8-23.5)$ \\
\hline \multicolumn{4}{|c|}{ Availability of after-hours access to primary care physician } \\
\hline Yes & $31.9(27.9-36.0)$ & $34.1(28.6-39.5)$ & $27.6(22.5-32.8)$ \\
\hline No & $68.1(64.0-72.1)$ & $65.9(60.5-71.4)$ & $72.4(67.2-77.5)$ \\
\hline \multicolumn{4}{|c|}{$\begin{array}{l}\text { Other health professionals (e.g., nurse practitioners, } \\
\text { nutritionists) in the primary care physician's office }\end{array}$} \\
\hline Yes & $24.2(20.9-27.4)$ & $22.9(18.9-26.9)$ & $26.8(21.1-32.5)$ \\
\hline No & $75.8(72.6-79.1)$ & $77.1(73.1-81.1)$ & $73.2(67.5-78.9)$ \\
\hline \multicolumn{4}{|c|}{ Other professionals involved in care in past $12 \mathrm{mo}$} \\
\hline Yes & $6.1 \quad(4.6-7.6)$ & $4.3(2.8-5.8)$ & $9.9 \quad(6.6-13.2)$ \\
\hline No & $93.9(92.4-95.4)$ & $95.7(94.2-97.2)$ & $90.1(86.8-93.4)$ \\
\hline \multicolumn{4}{|c|}{$\begin{array}{l}\text { Contact with a nurse in the prior } 12 \mathrm{mo} \text {, for care or advice } \\
\text { about chronic condition }\end{array}$} \\
\hline Never & $85.5(82.5-88.5)$ & $87.2(83.6-90.9)$ & $81.9(77.0-86.8)$ \\
\hline$\geq 1$ contacts & $14.5(11.5-17.5)$ & $12.8(9.1-16.4)$ & $18.1(13.2-23.0)$ \\
\hline \multicolumn{4}{|c|}{$\begin{array}{l}\text { Willing to see a nurse practitioner if primary care physician } \\
\text { not available }\end{array}$} \\
\hline Yes & $87.3(84.7-90.0)$ & $87.8(84.5-91.1)$ & $86.3(82.0-90.6)$ \\
\hline No & $12.7(10.0-15.3)$ & $12.2(8.9-15.5)$ & $13.7(9.4-18.0)$ \\
\hline
\end{tabular}


received care from the same primary care physician or nurse (Table 2). About two-thirds of respondents (68.1\%) indicated they did not have after-hours access to their regular medical doctor or place of care; this proportion was slightly higher among respondents with more than 1 chronic condition. Whereas nearly one-quarter of respondents (24.2\%) indicated that other health professionals such as nurse practitioners or nutritionists worked in the same office as their primary care physician, only $6.1 \%$ indicated that these other professionals were involved in their care $(9.9 \%$ among those with $>1$ chronic condition). About 1 in 7 (14.5\%) had seen or talked to a nurse about their chronic condition in the past year. Most respondents $(87.3 \%)$ indicated that they would be willing to see a nurse practitioner if their primary care physician was not available.

\section{Other health care use}

Only $20.4 \%$ of respondents reported they had seen a specialist about their chronic condition in the prior 12 months, although this proportion was significantly greater among those with 2 or more chronic conditions $(32.8 \%)$ than among those with 1 chronic condition (14.5\%) (Table 3). Most respondents who had not seen a specialist indicated this was either because they did not need to or their primary care physician did not recommend it $(96.1 \%)$. A total of $4.8 \%$ of respondents reported being admitted to hospital for their chronic condition in the previous 12 months, and $8.1 \%$ reported an emergency department visit specifically for their chronic condition. The proportions of chronic disease-related hospital admissions and emergency department visits were higher among respondents with 2 or more chronic conditions (11.1\% and $13.9 \%$, respectively) than among those with 1 chronic condition $(1.8 \%$ and $5.4 \%$, respectively). Of the respondents who reported an emergency department visit for their chronic condition, about one-third (i.e., $2.9 \%$ of the $8.1 \%$ of respondents who had used an emergency department for the chronic condition in the prior year) thought that their last visit could have been avoided if their regular provider had been available.

\begin{tabular}{|c|c|c|c|}
\hline \multirow[b]{2}{*}{ Health care use } & \multicolumn{3}{|c|}{ Group, \% $(95 \% \mathrm{Cl})^{*} \dagger$} \\
\hline & Total & 1 chronic condition & $\geq 2$ chronic conditions \\
\hline \multicolumn{4}{|l|}{$\begin{array}{l}\text { Contact with a specialist regarding the chronic } \\
\text { condition in the prior } 12 \mathrm{mo}\end{array}$} \\
\hline No contact & $79.6(76.4-82.8)$ & $85.5(81.9-89.1)$ & $67.2(61.1-73.4)$ \\
\hline$\geq 1$ contacts & $20.4(17.2-23.6)$ & $14.5(10.9-18.1)$ & $32.8(26.6-38.9)$ \\
\hline Prevalence rate ratio & - & - & $2.3(1.7-3.1)$ \\
\hline No. of contacts, mean $(95 \% \mathrm{Cl})$ & $1.03(0.1-2.1)$ & $0.4 \quad(0.2-0.6)$ & $2.3(0.0-5.3)$ \\
\hline \multicolumn{4}{|l|}{ Reasons for not seeing a specialist } \\
\hline Not required & $70.5(66.5-74.5)$ & $72.5(67.7-77.5)$ & $64.9(58.4-71.3)$ \\
\hline Doctor did not recommend it & $28.9(24.8-32.9)$ & $28.3(23.4-33.3)$ & $30.3(23.9-36.8)$ \\
\hline Other reason & $4.4(2.8-6.0)$ & $2.5(1.3-3.6)$ & $9.5(4.7-14.3)$ \\
\hline Either not required or doctor did not recommend it & $96.1(94.6-97.7)$ & $98.1(97.1-99.1)$ & $91.0(86.2-95.7)$ \\
\hline \multicolumn{4}{|l|}{$\begin{array}{l}\text { No. of different physicians and specialists seen in the } \\
\text { prior } 12 \text { mo }\end{array}$} \\
\hline 0 or 1 & $75.9(72.3-79.6)$ & $80.2(75.6-84.7)$ & $66.9(71.2-72.7)$ \\
\hline$>1$ & $24.1(20.4-27.7)$ & $19.8(15.3-24.4)$ & $33.1(27.3-38.8)$ \\
\hline \multicolumn{4}{|l|}{$\begin{array}{l}\text { No. of emergency department visits for the chronic } \\
\text { condition in the prior } 12 \mathrm{mo}\end{array}$} \\
\hline 0 & 91.9 (89.9-93.9) & $94.6(92.4-96.8)$ & 86.1 (81.9-90.3) \\
\hline$\geq 1$ & $8.1 \quad(6.1-10.1)$ & 5.4 (3.2-7.6) & $13.9 \quad(9.7-18.1)$ \\
\hline \multicolumn{4}{|l|}{$\begin{array}{l}\text { Respondent thought last emergency department visit } \\
\text { for the chronic condition could have been avoided if } \\
\text { regular provider had been available }\end{array}$} \\
\hline No & $97.1(95.8-98.3)$ & $98.0(97.0-99.0)$ & 95.0 (91.7-98.3) \\
\hline Yes & $2.9 \quad(1.7-4.2)$ & $2.0 \quad(1.0-3.0)$ & $5.0 \quad(1.7-8.3)$ \\
\hline \multicolumn{4}{|l|}{$\begin{array}{l}\text { Admission to hospital in prior } 12 \text { mo for chronic } \\
\text { condition }\end{array}$} \\
\hline No & 95.2 (93.7-96.7) & 98.2 (96.9-99.4) & 88.9 (84.9-93.0) \\
\hline Yes & $4.8 \quad(3.3-6.3)$ & $1.8 \quad(0.6-3.1)$ & $11.1 \quad(7.0-15.1)$ \\
\hline
\end{tabular}




\section{Aspects of health care use}

\section{No regular medical doctor}

Obesity and age less than 65 years were significantly associated with not having a regular medical doctor (Table 4). Obese respondents were 3 times more likely than nonobese respondents to report not having a regular medical doctor. Respondents less than 65 years of age were more than twice as likely as those aged 65 or older to not have a regular medical doctor.

\section{Other health care professionals involved in care}

Participants with diabetes (prevalence rate ratio [PRR] 3.5, 95\% confidence interval [CI] 2.2-5.7); those who lived in a rural area (PRR 1.7, 95\% CI 1.1-2.8); those who perceived their health to be good, fair or poor (PRR 1.9, 95\% CI 1.13.1); and those who lived in Alberta (PRR 2.8, 95\% CI 1.2-6.3, compared with residents of Manitoba, who had the lowest rate) were significantly more likely to report having other health care professionals involved in their care within the office of their primary care physician (Table 4).
Contact with a nurse in the last 12 months

None of the sociodemographic factors were associated with nurse involvement in management of respondents' chronic conditions. However, respondents with diabetes (PRR 3.2, 95\% CI 2.2-4.7) were significantly more likely to report having had a contact with a nurse about their chronic condition in the past 12 months, compared with those without diabetes (Table 4).

\section{Avoidable emergency department visit}

Respondents with a household income less than $\$ 30000$ (odds ratio [OR] 3.6, 95\% CI 1.5-8.4), no regular medical doctor (OR 6.8, 95\% CI 1.2-37.0), heart disease (OR 2.7, 95\% CI 1.2-6.2) or a prior stroke (OR 4.3, 95\% CI 1.3-15.0) were more likely to report that they had an emergency department visit that they thought could have been avoided had their regular provider been available (Table 4).

\section{Interpretation}

In this population-based survey of adults with 1 or more chronic conditions, we found that most respondents had a

\begin{tabular}{|c|c|c|}
\hline Outcome* & PRR or OR $(95 \% \mathrm{Cl}) \dagger$ & $p$ value \\
\hline \multicolumn{3}{|l|}{ No regular medical doctor, PRR } \\
\hline Obese & $3.0(1.6-6.0)$ & 0.001 \\
\hline Age $<65$ yr & $2.5(1.4-4.7)$ & 0.003 \\
\hline Male & $1.8(0.9-3.8)$ & 0.09 \\
\hline \multicolumn{3}{|c|}{$\begin{array}{l}\text { Other health care professionals in primary care physician's } \\
\text { office involved in care, PRR }\end{array}$} \\
\hline Diabetes & $3.5(2.2-5.7)$ & $<0.001$ \\
\hline Rural residence & $1.7(1.1-2.8)$ & 0.02 \\
\hline Poorer self-perceived health & $1.9(1.1-3.1)$ & 0.02 \\
\hline \multicolumn{3}{|l|}{ Province of residence } \\
\hline British Columbia & $1.3(0.6-2.8)$ & 0.5 \\
\hline Alberta & $2.8(1.2-6.3)$ & 0.02 \\
\hline Saskatchewan & $2.3(1.0-5.7)$ & 0.06 \\
\hline Manitoba (reference) & 1.0 & \\
\hline \multicolumn{3}{|c|}{$\begin{array}{l}\text { Contact with a nurse about chronic condition in prior } 12 \mathrm{mo} \text {, } \\
\text { PRR }\end{array}$} \\
\hline Diabetes & $3.2(2.2-4.7)$ & $<0.001$ \\
\hline Heart disease & $1.4(1.0-2.1)$ & 0.06 \\
\hline \multicolumn{3}{|c|}{$\begin{array}{l}\text { Respondent thought that last emergency department visit for } \\
\text { the chronic condition could have been avoided if regular } \\
\text { provider had been available, OR }\end{array}$} \\
\hline Household income $<\$ 30000$ & $3.6(1.5-8.4)$ & 0.003 \\
\hline No regular doctor & $6.8(1.2-37)$ & 0.03 \\
\hline Heart disease & $2.7(1.2-6.2)$ & 0.02 \\
\hline Stroke & $4.3(1.3-15)$ & 0.002 \\
\hline \multicolumn{3}{|c|}{$\begin{array}{l}\text { Note: } \mathrm{Cl}=\text { confidence interval, } \mathrm{OR}=\text { odds ratio, } \mathrm{PRR}=\text { prevalence rate ratio. } \\
\text { "Each outcome was modelled in a separate multivariable model, consisting only of the variables listed for that model. All items were based on } \\
\text { self-reported data. } \\
\dagger \text { All estimates and } 95 \% \mathrm{Cls} \text { are weighted and bootstrapped as per Statistics Canada guidelines. }\end{array}$} \\
\hline
\end{tabular}


regular medical doctor, although two-thirds did not have after-hours access to appointments outside traditional office hours. This is relevant because about one-third of respondents who visited an emergency department for their chronic condition thought the visit could have been avoided if their regular physician had been available. Importantly, respondents were willing to see other health care professionals, with most reporting that they would be willing to see a nurse practitioner if their primary care physician was not available. Respondents who were rural residents, had diabetes or lived in Alberta were more likely to have other health care professionals involved in their care.

Our finding that most people with chronic conditions have a regular medical doctor is similar to the results of 2 recent surveys, which reported that $96 \%$ of Canadians with at least 1 chronic condition had a regular doctor or place of care. ${ }^{10,11} \mathrm{We}$ found that younger or obese respondents were less likely to have a regular medical doctor. We also found that men were almost twice as likely to not have a regular doctor, although this was not statistically significant. Prior studies have reported that Canadians who were younger and male were less likely to have a regular physician. ${ }^{12}$ However, to our knowledge, the association between obesity and not having a regular physician has not previously been reported. Our finding that obese respondents were less likely to have a regular doctor is, however, consistent with studies that have found that obese individuals are less likely to obtain appropriate preventive care, independent of factors such as less education and lower income. ${ }^{13,14}$ Obese people may delay or avoid preventive care because of embarrassment and discomfort, ${ }^{14}$ anticipation of being told to lose weight ${ }^{15}$ and negative attitudes from providers. ${ }^{16}$ Given the numerous medical conditions associated with obesity, reduced access to primary care for these individuals is concerning.

Our study, as well as an earlier survey of Canadians with chronic conditions, ${ }^{10}$ found that two-thirds of respondents did not have access to after-hours appointments with their regular primary care physician. In addition, an international survey of adults with chronic disease in 8 countries found that Canada had the lowest rate of after-hours access and among the highest rates of emergency department use. ${ }^{17}$ Given that after-hours access to a regular primary care physician has been associated with less use of emergency departments for nonurgent problems, ${ }^{18}$ it is possible that some of the emergency department use perceived as avoidable by this population could be prevented through improving access to after-hours primary care.

Given that multidisciplinary care has previously been shown to be associated with positive outcomes in patients with chronic conditions, ${ }^{3-5}$ it is surprising that only $6 \%$ of respondents reported that allied health professionals were involved in the treatment of their chronic condition, which is a lower proportion than found in previous studies. ${ }^{17,19,20}$ The higher rate of such involvement in Alberta may have been because of Alberta's primary care networks, which have provided additional funds for management of chronic disease. ${ }^{21}$ Most respondents indicated they would be willing to see a nurse practitioner if their regular primary care physician wasnot available, and nurse practitioner-led clinics have been shown to be effective for chronic disease management. ${ }^{22-24}$ Thus, greater use of nurse practitioners in primary care practices, possibly including after-hours care, may be an option to improve access to primary care and outcomes for patients. However, the role that nurse practitioners will play in primary care remains a controversial topic. ${ }^{25}$

\section{Limitations}

Our study had several limitations. There are inherent limitations related to self-reported survey data, although these were minimized by Statistics Canada's rigorous methodology and expertise. Respondents' perceptions of whether an emergency department visit was avoidable may have been affected by response bias, and our lack of detailed clinical data limited our ability to adjust for illness severity in our regression models. It is possible that some respondents may have misinterpreted some questions, although the survey was tested and revised before implementation. Our estimates of the prevalence of allied health care involvement with patients may not be directly comparable to those obtained in other surveys because of differences in question wording. Recognizing that there are some interprovincial differences in health care delivery (e.g., drug insurance coverage), we believe that our main findings are likely generalizable to the rest of Canada.

\section{Conclusion}

This study involving western Canadians with selected chronic conditions identified key characteristics associated with barriers to primary care. These barriers included patient obesity, which is associated with a higher risk for poor outcomes. Importantly, we identified opportunities for greater involvement by allied health professionals in the care of patients with chronic conditions - in the office of the primary care physician or through greater use of nurse practitioners - that could help to address service gaps such as lack of after-hours access. Identifying and overcoming these barriers to care are key steps toward improving care and outcomes for patients with chronic disease.

\section{References}

1. Wagner EH, Austin BT, Davis C, et al. Improving chronic illness care: translating evidence into action. Health Aff (Millwood) 2001;20:64-78.

2. Bindman $\mathrm{AB}$, Grumbach $\mathrm{K}$, Osmond $\mathrm{D}$, et al. Preventable hospitalizations and access to health care. $7 A M A 1995 ; 274: 305-11$.

3. Hemmelgarn BR, Manns BJ, Zhang J, et al. Association between multidisciplinary care and survival for elderly patients with chronic kidney disease. 7 Am Soc Nephrol 2007;18:993-9.

4. Shojania KG, Ranji SR, McDonald KM, et al. Effects of quality improvement strategies for type 2 diabetes on glycemic control: a meta-regression analysis. 7AMA 2006;296:427-40

5. Zwar N, Harris M, Griffiths R, et al. A systematic review of chronic disease management. Canberra (Australia): Australian Primary Health Care Research Institute; 2006.

6. Canadian Community Health Survey (CCHS) Annual Component: User Guide 2011. Microdata files. Ottawa (ON): Statistics Canada; 2012

7. Barriers to care for people with chronic health conditions (BCPCHC). Ottawa (ON): Statistics Canada; 2012. Available: www23.statcan.gc.ca/imdb/p2SV.pl?Function=getSurvey\&SDDS=5189\&Item_Id=119656 (accessed 2013 Sept. 28).

8. Shields M, Connor Gorber S, Janssen I, et al. Bias in self-reported estimates of obesity in Canadian health surveys: an update on correction equations for adults. Health Rep 2011;22:35-45.

9. Barriers to care for people with chronic health conditions: microdata user guide. Ottawa (ON): Statistics Canada; 2012.

10. Disparities in primary bealth care experiences among Canadians with ambulatory care 
sensitive conditions. Ottawa $(\mathrm{ON})$ : Canadian Institute for Health Information; 2012.

11. How do sicker Canadians with chronic disease rate the health care system? Results from the 2011 Commonwealth Fund International Health Policy Survey of Sicker Adults. Toronto (ON): Health Council of Canada; 2011.

12. Talbot Y, Fuller-Thomson E, Tudiver F, et al. Canadians without regular medical doctors. Who are they? Can Fam Physician 2001;47:58-64.

13. Wee CC, McCarthy EP, Davis RB, et al. Screening for cervical and breast cancer: Is obesity an unrecognized barrier to preventive care? Ann Intern Med 2000; 132:697-704.

14. Wee CC, Phillips RS, McCarthy EP. BMI and cervical cancer screening among white, African-American, and Hispanic women in the United States. Obes Res 2005;13:1275-80.

15. Drury CA, Louis M. Exploring the association between body weight, stigma of obesity, and health care avoidance. 7 Am Acad Nurse Pract 2002;14:554-61.

16. Amy NK, Aalborg A, Lyons P, et al. Barriers to routine gynecological cancer screening for White and African-American obese women. Int 7 Obes (Lond) 2006;30:147-55.

17. Schoen C, Osborn R, How SK, et al. In chronic condition: experiences of patients with complex health care needs, in eight countries, 2008. Health Aff (Millwood) 2009;28:w1-16.

18. Howard M, Goertzen J, Kaczorowski J, et al. Emergency department and walk-in clinic use in models of primary care practice with different after-hours accessibility in Ontario. Healthc Policy 2008;4:73-88.

19. Canadians' experiences with chronic illness care in 2007. A data supplement to: Why bealth care renewal matters: learning from Canadians with chronic bealth conditions. Toronto (ON): Health Council of Canada; 2007.

20. Teams in action: primary bealth care teams for Canadians. Toronto (ON): Health Council of Canada; 2009.

21. Campbell DJ, Sargious P, Lewanczuk R, et al. Use of chronic disease management programs for diabetes: in Alberta's primary care networks. Can Fam Physician 2013; 59:e86-92.

22. New JP, Mason JM, Freemantle N, et al. Specialist nurse-led intervention to treat and control hypertension and hyperlipidemia in diabetes (SPLINT): a randomized controlled trial. Diabetes Care 2003;26:2250-5.

23. Strömberg A, Martensson J, Fridlund B, et al. Nurse-led heart failure clinics improve survival and self-care behaviour in patients with heart failure: results from a prospective, randomised trial. Eur Heart 7 2003;24:1014-23.
24. Ward DR, Novak E, Scott-Douglas N, et al. Assessment of the Siksika chronic disease nephropathy-prevention clinic. Can Fam Physician 2013;59:e19-25.

25. Donelan K, DesRoches CM, Dittus RS, et al. Perspectives of physicians and nurse practitioners on primary care practice. N Engl f Med 2013;368:1898-906.

Affiliations: Department of Medicine (Weaver, Manns, Campbell, Hemmelgarn); Department of Community Health Sciences (Manns, Sanmartin, Campbell, Hemmelgarn), University of Calgary, Calgary; Department of Medicine (Tonelli, Lewanczuk), University of Alberta, Edmonton, Alta.; Statistics Canada (Sanmartin, Hennessy), Ottawa, Ont.; Ottawa Hospital Research Institute (Ronksley, Hennessy), Ottawa, Ont.; Department of Family Medicine (Braun), Alberta Health Services, Calgary, Alta.

Contributors: All of the authors contributed to the conception and design of the study or the survey. Robert Weaver, Paul Ronksley and David Campbell analyzed the data, and all of the authors contributed to data interpretation. Robert Weaver and Brenda Hemmelgarn drafted the manuscript, which all of the other authors revised. All authors gave final approval of the version submitted for publication and are guarantors of the work.

Funding: This research was supported by an interdisciplinary team grant from Alberta Innovates-Health Solutions (the Interdisciplinary Chronic Disease Collaboration).

Acknowledgements: The authors acknowledge the assistance of Statistics Canada in conducting the survey and the Prairie Regional Research Data Centre in facilitating the data analysis. Marcello Tonelli and Braden Manns were supported by career salary awards from Alberta InnovatesHealth Solutions. Brenda Hemmelgarn was supported by the Roy and $\mathrm{V}_{1}$ Baay Chair in Kidney Research, and Marcello Tonelli was supported by a Canada Research Chair.

Supplemental information: For reviewer comments and the original submission of this manuscript, please see www.cmajopen.ca/content/2 /1/E27/suppl/DC1 